Check for updates

Cite this: Nanoscale Adv., 2021, 3, 1730

\title{
Binary and ternary Pt-based clusters grown in a plasma multimagnetron-based gas aggregation source: electrocatalytic evaluation towards glycerol oxidation
}

\author{
W. Chamorro-Coral, (D) *a A. Caillard, ${ }^{\text {a }}$ P. Brault, (D) ${ }^{a}$ S. Baranton (DD ${ }^{b}$ \\ and C. Coutanceau ${ }^{\mathrm{b}}$
}

\begin{abstract}
Platinum (Pt), platinum-bismuth (PtBi), platinum-copper (PtCu) and platinum-bismuth-copper (PtCuBi) clusters were grown in a gas aggregation source (GAS) equipped with three in-plane plasma magnetrons located in a single region of the gas aggregation zone. The X-ray diffraction results have shown that $\mathrm{PtCu}$ clusters form alloys as the decrease of the lattice parameter occurs when the $\mathrm{Cu}$ atomic content increases. PtBi clusters do not form alloys, but the presence of secondary Bi oxide phases was detected. Scanning transmission electron microscope mapping images revealed that simultaneously adding Bi and $\mathrm{Cu}$ to $\mathrm{Pt}$ leads to $\mathrm{PtCu}$ alloyed clusters decorated with $\mathrm{Bi}$ or CuBi species on the surface. The electrochemical results indicated that the shell might be composed of a metastable CuBi phase. Electrochemical measurements have shown that the addition of $\mathrm{Bi}$ or $\mathrm{Cu}$ to the Pt clusters enhances the catalytic activity for glycerol oxidation by decreasing the oxidation onset potential.
\end{abstract}

Received 1st December 2020 Accepted 19th January 2021

DOI: 10.1039/d0na01009j

rsc.li/nanoscale-advances complex mixtures, the selectivity. Electrocatalytic processes are surface reactions; therefore, the use of metallic clusters (diameter $<5 \mathrm{~nm}$ ) dispersed on a high surface carbon support can increase the specific surface area of electrocatalytic materials and help to drastically decrease the noble metal amount used in electrodes. Among these metals, Pt has been proved to be a good candidate due to its high activity and efficiency; however, some of its flaws are its high price, low availability, and high strategic character. To overcome these drawbacks, the use of multimetallic clusters that will decrease the Pt content while maintaining or even increasing the Pt performance is proposed. It has been shown that adding bismuth to Pt clusters decreases the glycerol oxidation onset potential and therefore the electric energy consumption. ${ }^{\mathbf{8} 9}$ The negative shift of the onset potential occurs because $\mathrm{Bi}$ atoms promote the formation of intermediate species that modify the glycerol oxidation mechanism. The modification of $\mathrm{Pt}$ with $\mathrm{Bi}$ also allows improving the selectivity by avoiding the dissociative adsorption of glycerol with $\mathrm{C}-\mathrm{C}$ bond breaking at low electrode potentials. Copper is also known to be a good co-catalyst. The modification of $\mathrm{Pt}$ with $\mathrm{Cu}$ enhances the catalytic activity for alcohol electro-oxidation and also allows decreasing the oxidation onset potential. ${ }^{\mathbf{1 0 - 1 2}}$

The aim of the present work is to grow multimetallic catalysts based on clusters with an admixture of $\mathrm{Pt}, \mathrm{Bi}$ and $\mathrm{Cu}$. The clusters were produced in a plasma-based gas aggregation source (GAS) using a multimagnetron approach, where each magnetron is powered independently. The multimetallic clusters supported on carbon form the electrocatalytic powders that
${ }^{a}$ Groupe de Recherches sur l'Energétique des Milieux Ionisés (GREMI), Université d'Orléans, CNRS, 14 rue d'Issoudun, BP6744, 45067 Orléans cedex 2, France. E-mail:wachamorroc@unal.edu.co

${ }^{b}$ Institut de Chimie des Milieux et Matériaux de Poitiers (IC2MP), Université de Poitiers, CNRS, 4 rue Michel Brunet, TSA 51106, 86073 Poitiers cedex 9, France 
will be tested for the electrochemical conversion of glycerol. Production of $\mathrm{Pt}$ and $\mathrm{Cu}$ clusters by means of a GAS based on magnetron sputtering has already been reported, ${ }^{13-17}$ while the growth of Bi clusters with less than 100 atoms using a GAS has only been described for pressures between $100 \mathrm{~Pa}$ and $2000 \mathrm{~Pa}$ and using thermal evaporation as the source for the metallic vapour. ${ }^{18,19}$ Recent reports have shown that the multimagnetron approach is a straightforward method to modify the composition of clusters during the synthesis of trimetallic nanoclusters. ${ }^{20-24}$ However, to our knowledge, this is the first time that multimetallic Pt-based clusters modified with $\mathrm{Cu}$ and/or Bi have been synthesized by means of a GAS assisted by a multimagnetron sputtering source. The electrochemical responses of Pt-cluster based electrodes, i.e. oxidation current density and/or onset potential, depend on the clusters properties that could be influenced by the experimental parameters of synthesis. Therefore, an objective of this work is to provide an insight about the relationship between the composition, nanostructure, and catalytic activity of the Pt-based clusters.

\section{Experimental setup}

Pt-based catalysts are synthesized using a GAS based on a multimagnetron source, allowing the production of clusters in a gas phase with optimal size control. ${ }^{25}$ The GAS setup is based on a commercial Nanogen 50 from Mantis Deposition Ltd and has been modified to include three magnetrons (ONYX, 1-inch in diameter, from Angstrom Sciences) with an independent positioning system that allows adjusting the position of each magnetron inside the aggregation source. Each of the $\mathrm{Pt}, \mathrm{Cu}$ and $\mathrm{Bi}$ targets $(99.99 \%$ purity) is mounted on one of the three magnetrons. The GAS chamber has dimensions of $30 \mathrm{~cm}$ length and $13 \mathrm{~cm}$ diameter: the distance between the three magnetrons and the GAS outlet orifice, $0.5 \mathrm{~cm}$ in diameter, is fixed to $7 \mathrm{~cm}$ (magnetrons are in an in-plane configuration). The argon flow rate is fixed to $80 \mathrm{sccm}$ (standard cubic centimeter) giving a total pressure in the aggregation chamber of $42 \mathrm{~Pa}$, which allows the gas-phase growth of clusters. By using such a device, alloyed, coreshell and Janus nanoclusters could be obtained depending on the experimental conditions and on the nature of the materials. ${ }^{20,24}$ The GAS is placed inside a high vacuum (HV) deposition chamber with a lower total pressure of about $0.4 \mathrm{~Pa}$ for an $80 \mathrm{sccm} \mathrm{Ar}$ flow rate (residual pressure of $10^{-4} \mathrm{~Pa}$ without argon introduction). An MKS type 1739A controller coupled to an MKS Type 247 readout was used to control the argon flow rate. The constant argon flow and the pressure difference between the GAS and the HV chamber generate a cluster beam from the GAS outlet orifice. The cluster beam passes through a quadrupole mass spectrometer (QMS, MesoQ from Mantis Deposition Ltd) collecting only the negatively charged clusters, which allows following in situ the cluster mass distribution. Using this procedure at least three curves were recorded for each deposition condition.

A mobile substrate-holder is placed in the HV deposition chamber between the GAS and the QMS, with a distance of $9 \mathrm{~cm}$ between the GAS orifice and the substrate. Fig. 1 gives an overview of the experimental setup based on the plasma multimagnetron. The deposition rate is estimated for each pure material using a quartz crystal microbalance (QCM) attached to a mobile holder and placed at the same distance from the GAS orifice as that for the substrate holder. When the monometallic Pt target is sputtered, the deposition rates vary between 0.7 and $1.1 \mathrm{mg} \mathrm{h}^{-1} \mathrm{~cm}^{-2}$ in the power range from $20 \mathrm{~W}$ to $30 \mathrm{~W}$, whereas for $\mathrm{Cu}$ the deposition rates vary from 0.1 to $0.6 \mathrm{mg} \mathrm{h}^{-1} \mathrm{~cm}^{-2}$ over the same power range as that for Pt. The deposition rate is not measurable for Bi owing to its low melting point $\left(271.4{ }^{\circ} \mathrm{C}\right)$ that limits the condensation process in the GAS ${ }^{18}$ and avoids the formation of Bi clusters. In the case of co-sputtering of multiple targets, the composition of clusters being a priori unknown, it is not possible to measure the cluster deposition rate with the quartz crystal microbalance.

Four types of clusters are produced: pure Pt clusters, bimetallic $\mathrm{PtCu}$ and PtBi clusters and trimetallic PtCuBi clusters. Magnetron sputtering was performed in direct current (DC) mode using a Pinnacle Plus generator (Advanced Energy) for Pt and Cu targets and an ion generator (Materials Science, Inc.) for the Bi target. To vary the cluster composition, the power applied on each magnetron $\left(\mathrm{Pt}_{X}, \mathrm{Cu}_{Y}\right.$ and $\left.\mathrm{Bi}_{Z}\right)$ is varied between $20 \mathrm{~W}$ and $30 \mathrm{~W}$ for Pt and $\mathrm{Cu}$, and between 8 and $13 \mathrm{~W}$ for Bi. $X, Y$ and $Z$ correspond to the power applied to the respective $\mathrm{Pt}, \mathrm{Cu}$ and Bi targets. Before each set of experiments, the targets are cleaned by sputtering during at least 5 min to obtain a stable voltage before moving the substrate holder in the beam. The influence of sputtering power on the cluster growth was evaluated by recording the in situ mass distribution curves measured by QMS. The curves follow a lognormal behaviour and after fitting, the average cluster mass $\left(C_{\text {avg-mass }}\right)$ is obtained. The grid current intensity is directly related to the number of negatively charged clusters and the area under the curve corresponds to the sum of all the clusters of different masses that come from the cluster beam, which can be interpreted as the total mass deposited $\left(m_{\text {total }}\right)^{26}$

For physical characterization, clusters are deposited for 3 min onto N-type doped $\mathrm{Si}$ (100, p-doped) and for 3 seconds on carbon-coated Ni or Cu TEM grids (300 mesh, SPI) depending on the presence or the absence of $\mathrm{Cu}$ in the clusters. Physical characterization includes grazing incidence X-ray diffraction (GIXRD) performed on a Bruker diffractometer fitted with a $\mathrm{Cu}$ X-ray source $\left(\lambda_{\mathrm{K}}=1.5418 \AA\right)$, energy-dispersive X-ray spectroscopy (EDX) using a Bruker QUANTAX X-ray detector mounted in a Zeiss Supra 40 scanning electron microscope and transmission electron microscopy (TEM) investigations using a JEMARM 200F Cold FEG TEM/STEM operating at $200 \mathrm{kV}$, equipped with a spherical aberration (Cs) probe and image correctors (point resolution $0.12 \mathrm{~nm}$ in TEM mode and $0.078 \mathrm{~nm}$ in STEM mode). The experimental diffraction signals from GIXRD and TEM are compared with calculated XRD patterns using VESTA software. ${ }^{27}$ Crystal structures are obtained from the Materials Project (MP) database where each structure has a unique identification number in the form mp- $x x x x .^{28}$

The clusters used to prepare the electrodes for the electrochemical measurements are collected for 10 minutes in a glass vial placed $3 \mathrm{~cm}$ from the cluster beam exit (Fig. 1). The resulting clusters are then dispersed in ethanol using an ultrasonic bath. The mass of collected clusters is obtained from the mass difference between the vial before and after deposition (instrumental error of $\pm 0.0001 \mathrm{~g}$ ). A calculated amount of carbon 


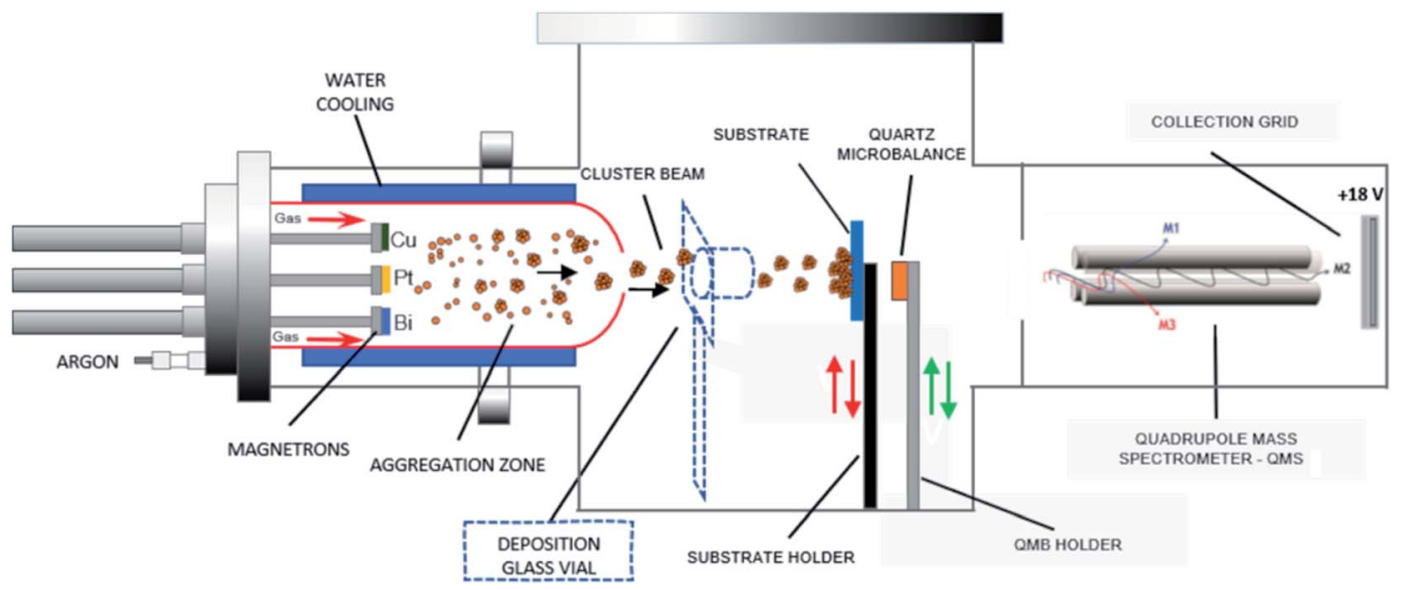

Fig. 1 Schematic of the adjustable multimagnetron based GAS used for the multimetallic cluster synthesis, adapted from a Mantis Nanogen 50 system.

(Vulcan XC72 thermally treated at $400{ }^{\circ} \mathrm{C}$ under a nitrogen atmosphere) is added to obtain a metal loading of $40 \mathrm{wt} \%$. Carbon powder and metal clusters are mixed and dispersed in ethanol. The suspension is sonicated for at least 20 minutes to ensure a uniform repartition of clusters on the carbon support. The suspension mixture is then filtered on a commercial alumina oxide membrane purchased from Sigma Aldrich (pore size of $0.2 \mu \mathrm{m}$, thickness of $0.1 \mathrm{~mm}$, diameter of $13 \mathrm{~mm}$ ) and dried. An ink of clusters/carbon powder in suspension in isopropanol is prepared and a $3 \mu \mathrm{L}$ aliquot is deposited onto a $3 \mathrm{~mm}$ diameter glassy carbon electrode, as described elsewhere. ${ }^{3}$ The $\mathrm{Pt} / \mathrm{C}, \mathrm{PtCu} / \mathrm{C}, \mathrm{PtBi} / \mathrm{C}$ and $\mathrm{PtCuBi} / \mathrm{C}$ electrodes are loaded with $0.08 \pm 0.01 \mathrm{mg}_{\mathrm{Pt}} \mathrm{cm}^{-2}, 0.09 \pm 0.01 \mathrm{mg}_{\mathrm{PtCu}} \mathrm{cm}^{-2}, 0.09 \pm 0.01$ $\mathrm{mg}_{\mathrm{PtBi}} \mathrm{cm}^{-2}$ and $0.10 \pm 0.01 \mathrm{mg}_{\mathrm{PtCuBi}} \mathrm{cm}^{-2}$, respectively. The electrochemical measurements are performed in a classical three-electrode cell with a reversible hydrogen electrode (RHE) as the reference, Pt-based catalytic powder deposited on a glassy carbon disk as the working electrode, and a glassy carbon plate as the counter electrode. Cyclic voltammetry (CV) measurements performed in a $\mathrm{N}_{2}$-purged $0.10 \mathrm{~mol} \mathrm{~L}^{-1} \mathrm{NaOH}$ electrolyte are recorded using a VersaSTAT 4 potentiostat between +0.050 and $+1.200 \mathrm{~V} v s$. RHE with a scan rate of $0.050 \mathrm{~V} \mathrm{~s}^{-1}$. The electrocatalytic activity is evaluated at a scan rate of $0.005 \mathrm{~V} \mathrm{~s}^{-1}$ in the presence of $0.10 \mathrm{~mol} \mathrm{~L}^{-1}$ glycerol in a $\mathrm{N}_{2}$-purged $0.10 \mathrm{~mol} \mathrm{~L}^{-1}$ $\mathrm{NaOH}$ electrolyte at $20^{\circ} \mathrm{C}$ after correction of the metal loading to assess mass activity. Because the accurate determination of the onset potential is very difficult, ${ }^{29}$ it is arbitrarily and reasonably defined in this work as the potential at which the anodic (oxidative) current reaches $1 \%$ of the maximum current peak, which is in the range of generally considered current values for the onset potential determination. ${ }^{8,30}$

\section{Results}

First, the influence of co-sputtering Pt and $\mathrm{Cu}$ or Bi at different powers on the cluster mass distribution curves was analyzed.
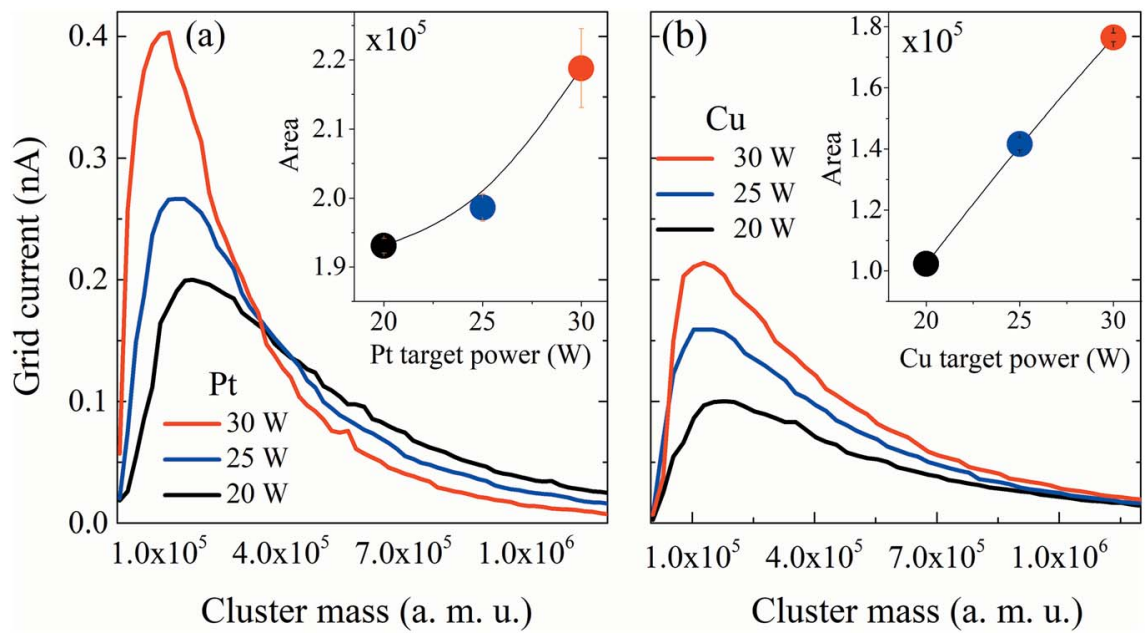

Fig. 2 Mass distribution curves obtained using QMS for Pt and Cu monometallic clusters grown at different sputtering powers. (a) Pt and (b) Cu clusters. Inset: area under the curve representing the total mass deposited ( $m_{\text {total }}$ ). For sputtering powers between $20 \mathrm{~W}$ and $30 \mathrm{~W}$, the mean cluster diameters, obtained from the lognormal fitting of the cluster mass distribution and assuming spherical clusters, range between 4.0 and $4.9 \mathrm{~nm}$ for Pt and between 6.0 and $6.5 \mathrm{~nm}$ for $\mathrm{Cu}$. 
Fig. 2a and b show the mass distribution curves of $\mathrm{Pt}$ and $\mathrm{Cu}$ monometallic clusters determined for different sputtering powers. The grid current intensity obtained for the Pt clusters (Fig. 2a) is higher than that obtained for the monometallic $\mathrm{Cu}$ ones (Fig. 2b). Although the sputtering yield $Y$ (thus the flux of sputtered atoms leaving the target) is higher for the $\mathrm{Cu}$ target than for the Pt one for the same sputtering power (at $30 \mathrm{~W}, Y_{\mathrm{Cu}}$ $=1.88, Y_{\mathrm{Pt}}=1.53$, calculated using SRIM software), more Pt clusters than $\mathrm{Cu}$ clusters are formed, showing that the condensation process is more effective for Pt atoms. Also, it is worth noting that a shift towards lower cluster average masses occurs in both $\mathrm{Pt}$ and $\mathrm{Cu}$ distribution curves when the sputtering power increases. This could be explained by a modification in the condensation process: high sputtering powers increase the number of atoms in the vapor phase, therefore increasing the probability of collisions, leading to the formation of more clusters but with lower average masses. Another aspect to consider is the area under the curves (Fig. 2, inset) which reveals an increase of the deposited mass $\left(m_{\text {total }}\right)$ with the sputtering power for both metals. This shows that an increase of the total number of clusters leads to an overall increase of $m_{\text {total }}$. It is worth noting that the Pt cluster mass increases approximately by only $15 \%$, while that of $\mathrm{Cu}$ increases by $c a$. $80 \%$ when the power is increased by $50 \%$ from 20 to $30 \mathrm{~W}$. The mean size of clusters can be obtained from the lognormal fitting of the cluster mass curve by assuming that clusters are spherical in shape; the sizes range from 4.0 to $4.9 \mathrm{~nm}$ for Pt clusters and from 6.0 to $6.5 \mathrm{~nm}$ for $\mathrm{Cu}$ clusters.

After reviewing the influence of the sputtering power on the average masses and mean cluster sizes of monometallic Pt and $\mathrm{Cu}$ clusters, the influence of the power applied to the $\mathrm{Pt}, \mathrm{Cu}$ and $\mathrm{Bi}$ targets for the formation of $\mathrm{Pt}-\mathrm{Cu}$ and $\mathrm{Pt}-\mathrm{Cu}-\mathrm{Bi}$ clusters by co-sputtering is also studied (Fig. 3). For Pt and $\mathrm{Cu}$ co-sputtering (Fig. 3a), the Pt sputtering power is fixed at $25 \mathrm{~W}$, while the $\mathrm{Cu}$ sputtering power is increased from $0 \mathrm{~W}$ to $30 \mathrm{~W}$. A positive jump of current occurs between $0 \mathrm{~W}$ and $15 \mathrm{~W}$, but a further increase of the $\mathrm{Cu}$ sputtering power leads to a slight decrease of the mass distribution intensity as well as to a weak shift towards bigger cluster size (peak maximum at $1.2 \times 10^{5}$ amu for $20 \mathrm{~W}$ and 1.8 $\times 10^{5}$ amu for $30 \mathrm{~W}$ ). Considering the total mass deposited (Fig. 3a, inset), a jump between 0 and $15 \mathrm{~W}$ is also observed (increase of the area by more than $20 \%$ ). For the formation of trimetallic clusters (Fig. 3b), the $\mathrm{Pt}$ and $\mathrm{Cu}$ sputtering powers are kept constant at $25 \mathrm{~W}$ and $30 \mathrm{~W}$, respectively, and the $\mathrm{Bi}$ target sputtering power is increased from $0 \mathrm{~W}$ to $12 \mathrm{~W}$. From $0 \mathrm{~W}$ to $10 \mathrm{~W}$, the mass distribution curves remain almost unchanged except for a small but constant decrease of the mass distribution intensity. For a sputtering power of $12 \mathrm{~W}$ applied at the Bi target, the number of clusters decreases remarkably. Regarding the mass deposited, $m_{\text {total }}$ (inset of Fig. $3 \mathrm{~b}$ ), it increases until a sputtering power of $8 \mathrm{~W}$ is applied, then it starts to decrease especially for the sputtering power of $12 \mathrm{~W}$. Finally, the results presented in Fig. 3 highlight the synergy between $\mathrm{Pt}$ and $\mathrm{Cu}$ that leads to the increase of the cluster size and of the deposited mass, while the addition of Bi seems to limit the condensation and growing processes for sputtering powers higher than $8 \mathrm{~W}$.

As stated previously, the cluster composition can be varied by modifying each magnetron sputtering power. However, factors such as the target erosion profile and surface target composition are difficult to control under given sputtering conditions, and continuous changes in these parameters during the synthesis process introduce uncertainties in atomic compositions. The composition of catalysts used for electrochemical characterization was estimated by the semiquantitative EDX method: ${ }^{31}(76 \pm 8)$ at $\%$ and $(23 \pm 8)$ at $\%$ for $\mathrm{Pt}$ and $\mathrm{Cu}$, respectively, in the PtCu catalyst, $(92 \pm 8)$ at $\%$ and $(8 \pm 6)$ at $\%$ for Pt and Bi, respectively, in the PtBi catalyst, and (79 \pm 2$)$ at $\%$, $(18 \pm 11)$ at $\%$ and $(4 \pm 2$ at $\%)$ for $\mathrm{Pt}, \mathrm{Cu}$ and $\mathrm{Bi}$, respectively, in the PtCuBi catalyst. It is also worth saying that the overlapping of the Si peak (from the substrate) with the Pt peak and that of $\mathrm{Pt}$ peaks with Bi peaks could result in an underestimation of $\mathrm{Pt}$ and/or Bi atomic compositions. The measurements were performed on clusters deposited onto silicon substrates. Oxygen is
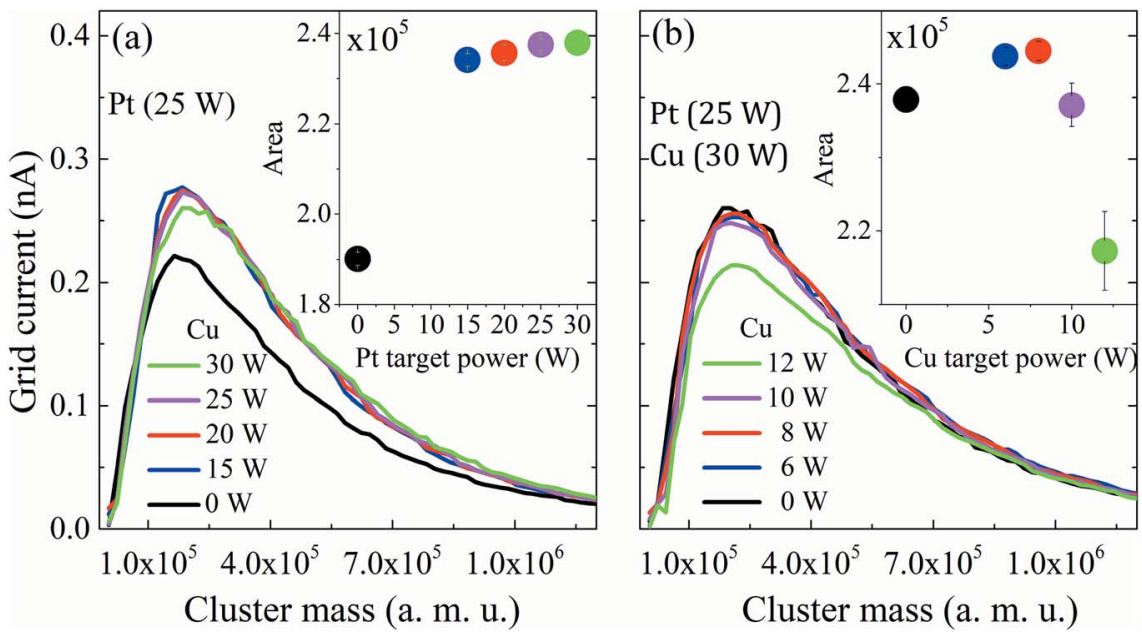

Fig. 3 Mass distribution curves obtained from QMS for multimetallic clusters grown under different sputtering powers of Pt, $\mathrm{Cu}$ and $\mathrm{Bi}$. (a) PtCu and (b) PtCuBi clusters. Inset: area under the curve representing the total deposited mass ( $\left.m_{\text {total }}\right)$. 
detected in all metallic clusters, but with higher contents in those containing $\mathrm{Cu}$ and/or $\mathrm{Bi}$, showing the high reactivity of these metals towards the residual oxygen present in the GAS. This can be explained by the increasing Gibbs oxidation energy in the $\mathrm{Pt}$, Bi and $\mathrm{Cu}$ series. ${ }^{32}$ Oxygen content was obtained by Rutherford Backscattering Spectroscopy (not shown here) using $2 \mathrm{MeV}$ alpha particles. The RBS results give a ratio of $c a .30$ at $\%$ of $\mathrm{O}$ but this value could be overestimated because the deposit of clusters on the Si substrate is inhomogeneous, which makes the RBS profile ambiguous and difficult to construe; therefore the fitting of the spectra could lead to inaccurate results.

Determination of the compositions of the multimetallic clusters does not give any information on whether they form mixtures of metals or alloys. Hence, crystal structures of the Ptbased clusters have been explored. GIXRD is performed on the clusters deposited on a Si wafer. To avoid artefacts due to difference in mass deposited on the wafer, all diffractograms are normalized with respect to the total area under the corresponding GIXRD patterns. Fig. 4 presents the diffraction pattern of Pt clusters with signals peaking at $39.75^{\circ}$ and $46.23^{\circ}$ that correspond to the (111) and (200) diffraction planes of the face-centered cubic (fcc) phase of Pt (mp-126 (ref. 28)), respectively. The diffraction pattern of PtBi clusters displays the main diffraction peaks corresponding to the Pt fcc phase, but broader in shape and with lower intensities. Additionally, a broad signal centered at $29^{\circ}$ is assigned to overlapped diffraction signals from phases such as Bi (mp-23152 (ref. 28)), PtBi (mp-1066078 (ref. 28)) and Bi oxide (mp-23262 (ref. 28)), which therefore prevents correct indexation. The peak broadening can be due to

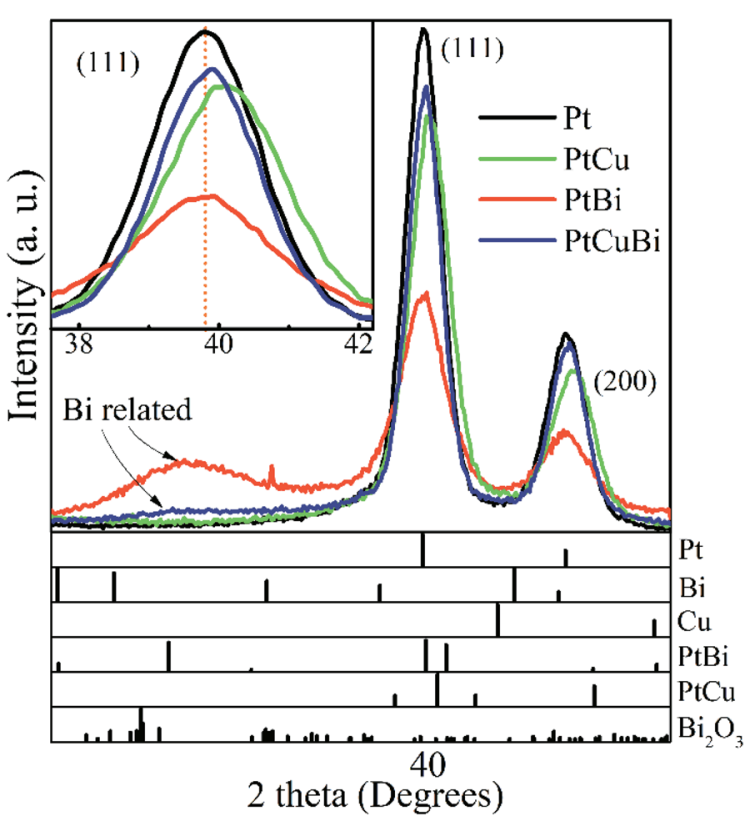

Fig. 4 Grazing incident X-ray diffractograms of Pt, PtBi, PtCu and PtCuBi clusters and (bottom) calculated XRD patterns of Pt (mp-126 (ref. 28)), Bi (mp-23151 (ref. 28)), Cu (mp-30 (ref. 28)), PtBi (mp1066078 (ref. 28)), $\mathrm{PtCu}\left(\mathrm{mp}-644311\right.$ (ref. 28)) and $\mathrm{Bi}_{2} \mathrm{O}_{3}$ (mp-23262 (ref. 28)). Inset: zoomed-in image of the (111) diffraction peak of the Ptbased clusters; the dashed line (orange) is a visual reference. crystallographic domains of short coherence lengths that exist in clusters of small sizes (diameter $<1 \mathrm{~nm}$ ) or of poor crystallinity. PtCu clusters lead to the same diffraction peaks as those for the Pt fcc phase but slightly shifted towards higher values. For the trimetallic clusters, the GIXRD pattern displays slight shifts of the diffraction peaks (compared to the pure Pt phase) towards higher $2 \theta$ values owing to the presence of the $\mathrm{Cu}$ atoms and a weak signal close to $29^{\circ}$ that is assigned to the presence of Bi oxide phases. The inset in Fig. 4 compares the position of the (111) diffraction peak maxima recorded for the different mono-, bi- and tri-metallic clusters.

Changes in the crystal structure of bi- and tri-metallic clusters with respect to monometallic $\mathrm{Pt} / \mathrm{C}$ were followed as a function of the sputtering power by focusing on the position of the (111) diffraction peak. Fig. 5 reveals the shift in position of the (111) diffraction peak and the induced change of the value of the lattice parameter, $a$, as a function of the ratio of the sputtering powers $P_{\mathrm{Bi}} / P_{\mathrm{Pt}}$ (Fig. 5a) and $P_{\mathrm{Cu}} / P_{\mathrm{Pt}}$ (Fig. 5b). The (111) peak of Pt clusters is located at $39.760^{\circ}$, close to that of bulk Pt $\left(39.755^{\circ}\right)$. When increasing the $\mathrm{Bi}$ content in clusters, the position of the (111) peak does not change, remaining in the measurement error bars. For the PtCu and the PtCuBi clusters, the position of the (111) peak shifts to higher $2 \theta$ values, and therefore to lower Pt lattice parameters.

$\mathrm{Cu}$ and $\mathrm{Pt}$ both crystallize in the fcc structure and the decrease of the interatomic distances in the cell (shrinkage of the crystal lattice) is due to the formation of a PtCu alloy as already reported. ${ }^{33,34}$ If the $\mathrm{Pt}-\mathrm{Cu}$ system followed Vegard's law, the $\mathrm{Cu}$ content in PtCu clusters would be approximately 5 at\% while for the PtCuBi it would be less than $5 \%$. These results are below the percentage expected from EDX and RBS measurements ( $\sim 20$ at $\%)$; these under-estimations of the Cu content by Vegard's law are due to the fact that at the nanoscale, Vegard's law can lead to inaccurate results. ${ }^{35-37} \mathrm{~A}$ non-uniform distribution of the atoms within the clusters leads to deviations from Vegard's law; however, GIXRD data also fail to verify the presence of Janus-type, core-shell type or intermixed type structures. ${ }^{35,36}$ Such deviations are driven by compressive strain forces due to differences in atom sizes and thus different unit cell volumes (11.8 $\AA^{3}$ for $\mathrm{Cu}$ and $15.8 \AA^{3}$ for $\mathrm{Pt}$ ).

To look in more detail at the nanostructure of the clusters, Fig. 6 presents TEM and high resolution TEM micrographs (HRTEM) of Pt-based clusters: Pt (Fig. 6a), PtCu (Fig. 6b) and PtCuBi (Fig. 6c). Fig. 6a- left shows mainly faceted clusters with an average size of $5 \mathrm{~nm}$ which is close to that obtained from the distribution curves of Fig. 2. The fast Fourier transformation (FFT) pattern in Fig. 6a - right confirms the presence of (111), (100) and (110) families of diffraction planes with distances of $0.228 \pm 0.003 \mathrm{~nm}, 0.198 \pm 0.002 \mathrm{~nm}$ and $0.140 \pm 0.001 \mathrm{~nm}$, respectively, corresponding to the values for a bulk Pt material. For clusters that are smaller than $4 \mathrm{~nm}$ the shape of the projection of faceted clusters resembles that obtained for truncated octahedra (Fig. 6a - center), with a higher proportion of low surface energy (111) facets $\left(1.49 \mathrm{~J} \mathrm{~m}^{-2}\right)$ and lower proportions of $(110)$ facets $\left(1.68 \mathrm{~J} \mathrm{~m}^{-2}\right.$ for the reconstructed facet) and (200) facets $\left(1.86 \mathrm{~J} \mathrm{~m}^{-2}\right) .{ }^{38}$ For such small clusters, interplanar distances of $0.224 \pm 0.003 \mathrm{~nm}, 0.194 \pm 0.002 \mathrm{~nm}$ 


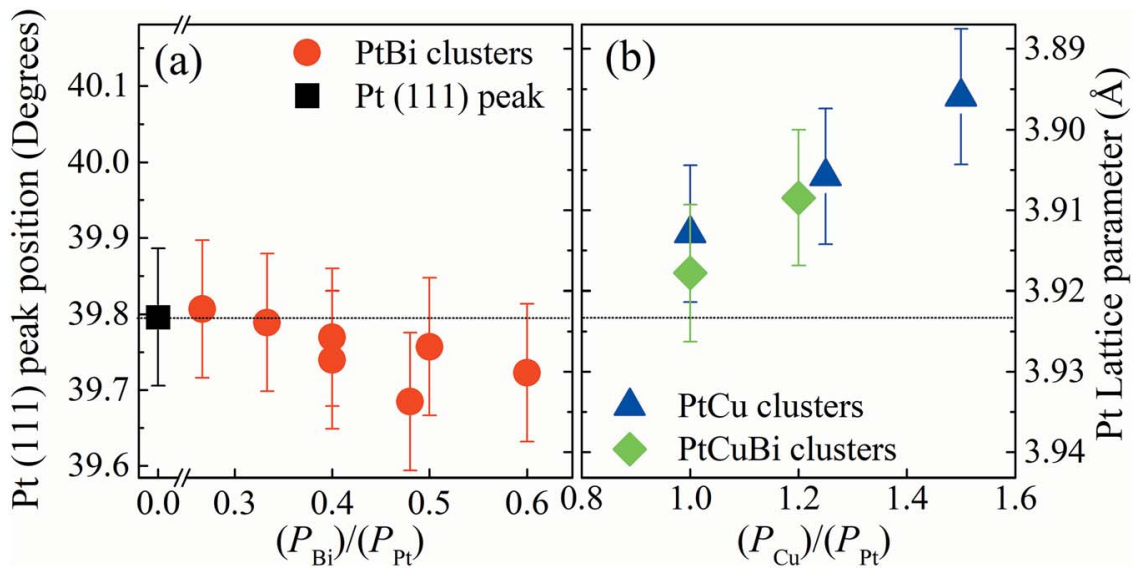

Fig. 5 Left axis: X-ray diffraction peak position of the (111) plane of the Pt fcc crystal lattice. Right axis: lattice parameter for (a) Pt clusters (black square), PtBi clusters (red circles), (b) PtCu clusters (blue triangles) and PtCuBi clusters (green diamonds). The $X$ axis corresponds to the ratio of the powers applied on $\mathrm{Bi}$ or $\mathrm{Cu}$ magnetrons compared to the power on the Pt magnetron $\left(P_{\mathrm{x}} / P_{\mathrm{Pt}}\right)$ with $\mathrm{x}=\mathrm{Bi}, \mathrm{Cu}$.
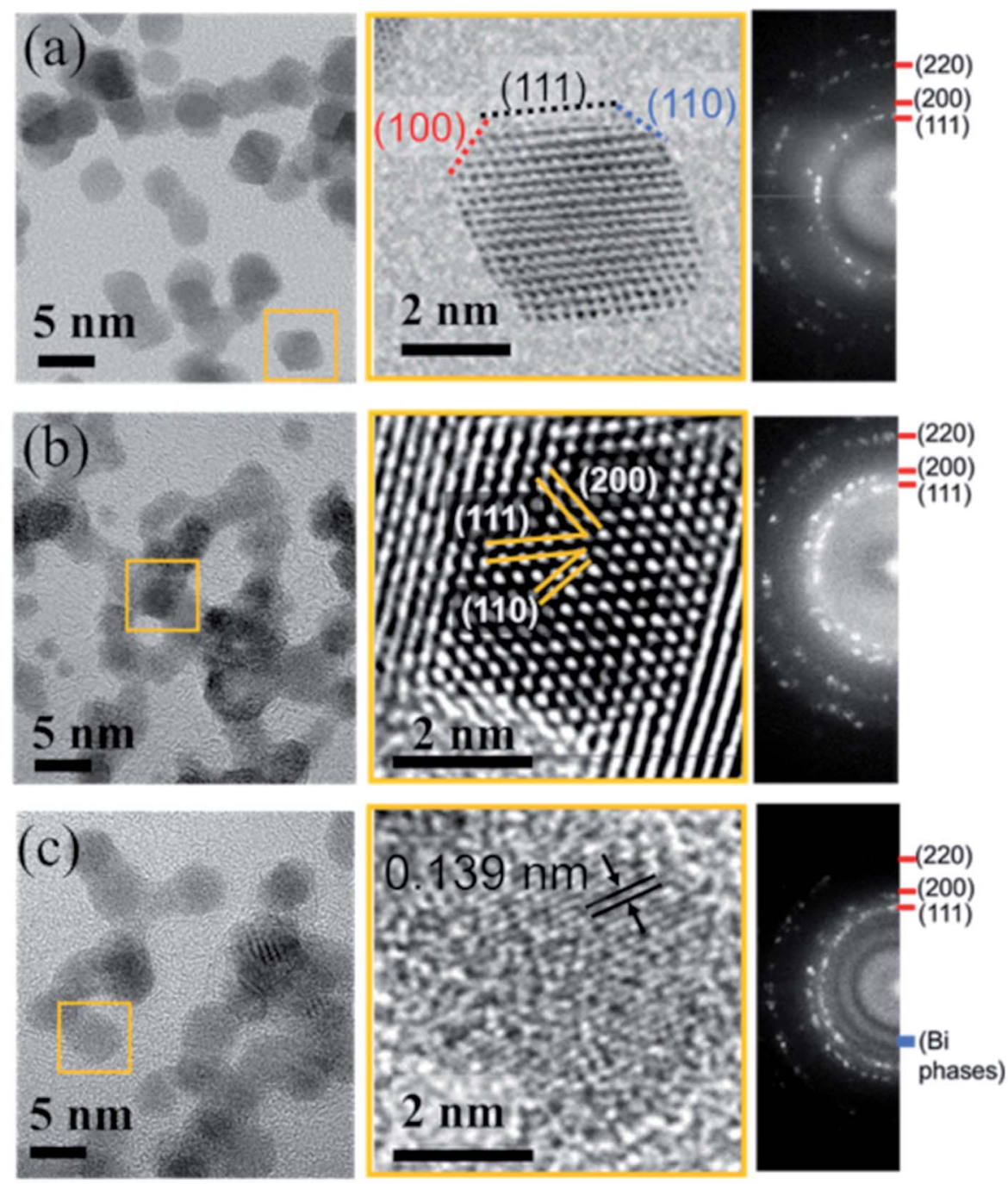

Fig. 6 High resolution TEM micrographs (left), zoomed-in image of single clusters (center) and corresponding fast Fourier transformation patterns (right) for (a) Pt, (b) PtCu and (c) PtCuBi clusters. 
and $0.135 \pm 0.002 \mathrm{~nm}$ for the (111), (200) and (110) diffraction planes, respectively, are lower than those determined for bigger clusters, which could indicate a shrinkage of the crystal lattice due to internal stress as observed for fcc clusters at the nanoscopic scale due to their high surface stress. ${ }^{39,40}$

Regarding PtCu bimetallic clusters, the TEM micrograph (Fig. 6b - left) shows highly aggregated clusters of $4.5 \mathrm{~nm}$ average size, and regions with shorter coherence domains compared to pure Pt clusters. As observed in Fig. 3, when Pt and $\mathrm{Cu}$ are co-sputtered, the number of clusters formed is higher than that for Pt sputtering alone, and this phenomenon could be responsible for a cluster aggregation process. In agreement with GIXRD results (Fig. 4), the crystallographic structure of clusters does not change when their aggregation occurs as confirmed by the FFT pattern on Fig. $6 \mathrm{~b}$ - right showing that the crystallographic planes correspond to those of the Pt fcc phase. A zoomed-in image of a highly ordered region (Fig. $6 \mathrm{~b}$ - center) confirms the presence of the Pt crystallographic planes. The TEM micrograph of ternary clusters PtCuBi (Fig. 6c - left) shows highly aggregated clusters with a lower crystal quality. Also, only round-shaped clusters are observed. Isolated clusters can have a size as low as $3.5 \mathrm{~nm}$ while aggregated clusters can reach $5.5 \mathrm{~nm}$. The FFT pattern (Fig. 6c - right) shows the presence of Pt diffraction planes, but also that of an additional region of relatively high intensity that could be related to diffraction planes of $\mathrm{Bi}$ phases (metallic, oxide or alloyed with $\mathrm{Pt}$ ) as observed by GIXRD in Fig. 4. A zoomed-in image of the micrograph (Fig. 6c - center) reveals mostly diffraction planes that have short coherence distances, such as (110) Pt planes, confirming the poor crystallinity of tri-metallic clusters.

To understand the poor crystallinity of ternary clusters, detailed nano-structural analysis is needed. EDX-STEM maps of ternary PtCuBi clusters are obtained. Fig. 7 shows, separately, the HAADF-STEM image of the PtBiCu clusters (Fig. 7a), the distribution of the three elements in the clusters (Fig. 7b) and the distribution of each element, $\mathrm{Pt}, \mathrm{Cu}$ and $\mathrm{Bi}$, in the clusters (Fig. 7c-e, respectively). On the one hand, $\mathrm{Pt}$ and $\mathrm{Cu}$ are homogeneously distributed along each cluster, which is in accordance with the formation of a PtCu alloy. On the other hand, $\mathrm{Bi}$ is mainly distributed on the borders of the clusters and on the grain-boundaries. This could give us the insight that ternary PtCuBi clusters present the structure of an alloyed PtCu core surrounded by a Bi shell. Molecular dynamic simulations have already confirmed such a kind of core-shell structure for the Pt-Bi system grown using a GAS, having its origins in stronger Pt-Bi bonding energy than for Pt-Pt. ${ }^{8}$ This result agrees with other studies where $\mathrm{Bi}$ atoms always decorate the $\mathrm{Pt}$ surface and bond to two or three Pt atoms depending on the Bi content. $^{\mathbf{8 , 4 1 - 4 3}}$ The MP database ${ }^{28}$ indicates that three stable alloys can be found for the $\mathrm{Pt}-\mathrm{Cu}$ system, while two stable alloys are present for the $\mathrm{Pt}-\mathrm{Bi}$ system. There are no data for binary alloys between $\mathrm{Cu}$ and $\mathrm{Bi}$ or ternary alloys between $\mathrm{Pt}, \mathrm{Cu}$ and $\mathrm{Bi}$ but a metastable $\mathrm{Cu}-\mathrm{Bi}$ alloy could be formed. ${ }^{\mathbf{4 4 , 4 5}}$ Considering only the stable phases, Pt will preferentially alloy with $\mathrm{Cu}$ (and not with $\mathrm{Bi}$ ) and $\mathrm{Cu}$ will be segregated from $\mathrm{Bi}$; however the database compounds are calculated at $0 \mathrm{~K}$ and 0 atm and sputtering is a synthesis technique far-from-equilibrium.

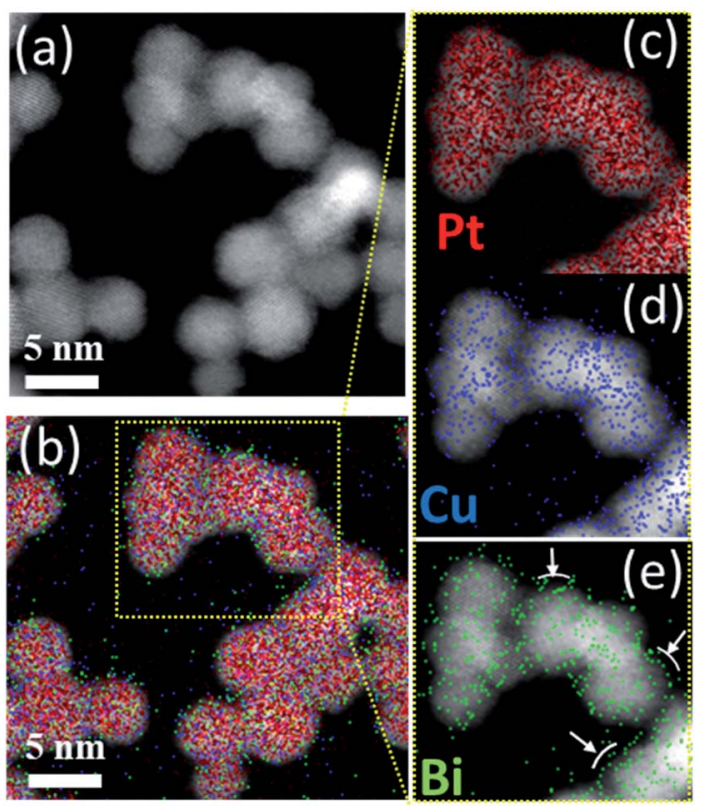

Fig. 7 (a) HAADF-STEM and (b) STEM/EDX elemental mapping images of $\mathrm{Pt}, \mathrm{Cu}$ and $\mathrm{Bi}$ atom distribution in PtCuBi clusters. Enlarged STEM/ EDX elemental mapping images for (c) Pt, (d) $\mathrm{Cu}$ and (e) $\mathrm{Bi}$ atom distribution in PtCuBi clusters.

Therefore, the presence of metastable phases cannot be discarded.

Due to differences in the growing process, properties such as crystallinity, lattice parameters and the nanostructure of the Ptbased clusters slightly change depending on the formation of mono-, bi- and tri-metallic clusters and these differences could affect their performances as electrocatalysts. For example, atom size differences between $\mathrm{Pt}$ and $\mathrm{Cu}$ in binary $\mathrm{PtCu}$ and ternary PtCuBi materials lead to differences in electronegativity that are responsible for d-band edge downshift, ${ }^{36}$ with a possible change in the oxidative catalytic activity. Therefore, their electroactivity was evaluated by cyclic voltammetry. This electrochemical technique allows obtaining detailed information on the cluster surfaces because only electroactive surface atoms are probed. Fig. 8 displays the fifth stable cyclic voltammogram (CV) of Ptbased electrodes recorded in a $\mathrm{N}_{2}$-purged $0.10 \mathrm{~mol} \mathrm{~L}^{-1} \mathrm{NaOH}$ electrolyte between +0.050 and $+1.200 \mathrm{~V} v s$. RHE at $0.050 \mathrm{~V} \mathrm{~s}^{-1}$.

The CVs can be differentiated between those recorded on materials without $\mathrm{Bi}, \mathrm{Pt} / \mathrm{C}$ and $\mathrm{PtCu} / \mathrm{C}$ catalysts, and those recorded on materials containing $\mathrm{Bi}, \mathrm{PtBi} / \mathrm{C}$ and $\mathrm{PtCuBi} / \mathrm{C}$ catalysts. The $\mathrm{Pt} / \mathrm{C}$ catalyst (black line) displays the typical $\mathrm{CV}$ signature of polycrystalline platinum nanoparticles in alkaline solution with the appearance of redox features related to the underpotential $\mathrm{H}$ adsorption $\left(\mathrm{H}_{\mathrm{UPD}}\right)$ and desorption of adsorbed $\mathrm{H}_{\mathrm{UPD}}$ in the +0.050 to $+0.400 \mathrm{~V} v s$. RHE range, and the features are related to platinum surface oxidation from $c a$. $0.600 \mathrm{~V} v s$. RHE for the positive potential variation. In the negative potential variation, the Pt surface oxides are reduced giving rise to the reduction peak centered at $c a$. $+0.750 \mathrm{~V} v s$. RHE.

The $\mathrm{PtCu} / \mathrm{C}$ catalyst (green line) also shows $\mathrm{H}$ and $\mathrm{O}$ interactions with the Pt surface. It is worth noting that no redox peak 


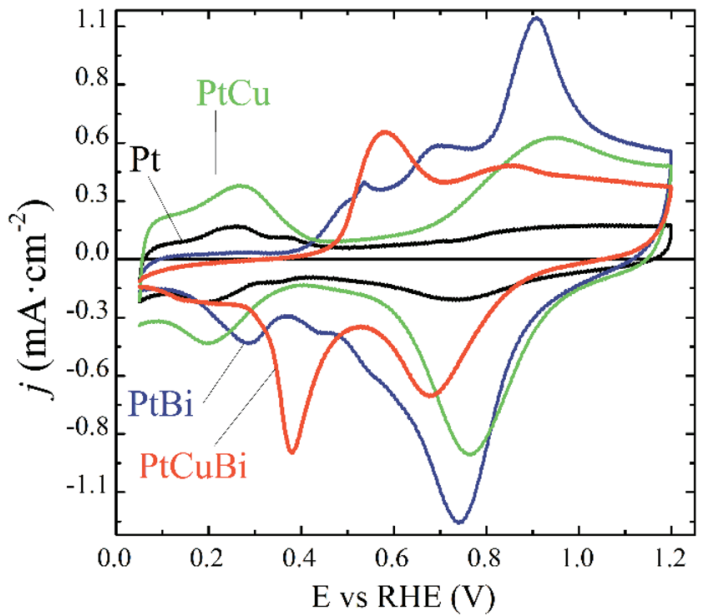

Fig. 8 Fifth stable cyclic voltammograms of Pt/C (black line), PtCu/C (green line), $\mathrm{PtBi} / \mathrm{C}$ (blue line) and $\mathrm{PtCuBi} / \mathrm{C}$ (red line) materials recorded between +0.050 and $+1.200 \mathrm{~V} v$ s. $\mathrm{RHE}\left(v=0.050 \mathrm{~V} \mathrm{~s}^{-1}, \mathrm{~N}_{2^{-}}\right.$ saturated $0.10 \mathrm{~mol} \mathrm{~L}^{-1} \mathrm{NaOH}$ electrolyte, $T=20^{\circ} \mathrm{C}$ ).

related to $\mathrm{Cu}$ oxidation/reduction is detected, revealing the stability of the $\mathrm{PtCu}$ surface alloy. ${ }^{46}$ Higher oxidation and reduction currents in the $+0.600 \mathrm{~V} v s$. RHE to $+1.200 \mathrm{~V} v s$. RHE range, i.e. in the potential region of $\mathrm{Pt}$ surface oxidation and reduction, are recorded, which seems to indicate that Pt surface atoms and $\mathrm{Cu}$ surface atoms are in strong interactions leading to the simultaneous formation/reduction of $\mathrm{Pt}$ and $\mathrm{Cu}$ surface oxides.

The addition of Bi to Pt and PtCu leads to two main changes in the CVs. First, the $\mathrm{H}_{\text {UPD }}$ adsorption/desorption peaks are suppressed, as observed elsewhere, ${ }^{9}$ revealing changes in the cluster surface. These changes come from physical alterations such as the Pt surface covering of bismuth atoms or from electronic perturbations at the Pt surface due to Bi-Pt interactions. The second feature is the presence of additional peaks centered at $+0.530,+0.680$ and $+0.880 \mathrm{~V} v$ vs. RHE for the PtBi catalyst and at +0.580 and $+0.850 \mathrm{~V} v$ s. RHE for the PtCuBi catalyst, for the positive potential variation.

In the case of $\mathrm{PtBi} / \mathrm{C}$, the shape of the $\mathrm{CV}$ greatly resembles that obtained on a $\mathrm{Pt}_{0.8} \mathrm{Bi}_{0.2} / \mathrm{C}$ catalyst prepared by a wet chemistry method (water in oil microemulsion), ${ }^{8}$ which contradicts the EDX analysis. The oxidation peaks located at $c a$. $+0.500 \mathrm{~V},+0.700 \mathrm{~V}$ and $+0.900 \mathrm{~V} v s$. RHE in the CV of a $\mathrm{Pt}_{0.8} \mathrm{Bi}_{0.2} /$ $\mathrm{C}$ material prepared with the water in oil microemulsion ${ }^{8}$ have been assigned to the oxidation reaction of bismuth according to eqn (1). The existence of different redox features is related to the level of interaction between Bi species and Pt surface atoms: the lower the interaction between both metals, the lower the oxidation potential of $\mathrm{Bi}^{8}$

$$
\mathrm{Bi}+6 \mathrm{OH}^{-} \rightleftharpoons \mathrm{Bi}_{2} \mathrm{O}_{3}+3 \mathrm{H}_{2} \mathrm{O}+6 \mathrm{e}^{-}
$$

The fact that plasma sputtering and wet chemistry methods lead to materials exhibiting the same electrochemical behavior indicates that the surfaces of both catalysts have the same structure. Therefore, the oxidation peak above $+0.800 \mathrm{~V} v s$. RHE can be related to the simultaneous formation of Pt and Bi oxides, as in the cases of PtBi materials from wet chemistry synthesis, and the signals between +0.500 and $+0.800 \mathrm{~V} v s$. RHE are related to the formation of Bi oxides. ${ }^{9}$ These oxidation peaks give rise to a main reduction peak centered at $c a .+0.730 \mathrm{~V} v s$. RHE, shoulders at $c a$. +0.550 and $c a .+0.450 \mathrm{~V} v s$. RHE and a second peak at $c a .+0.280 \mathrm{~V} v s$. RHE for the negative potential variation.

In the case of the PtCuBi catalyst, only two oxidation peaks (at +0.580 and $+0.850 \mathrm{~V} v$ s. RHE) are observed for the positive potential variation (instead of three for the PtBi catalyst), giving rise to only two reduction peaks for the negative variation of potential. The oxidation peak at higher potential is already visible for PtCu and PtBi and could reasonably by assigned to the simultaneous oxidation of $\mathrm{Pt}, \mathrm{Bi}$ and $\mathrm{Cu}$ surface atoms. The one at lower potential is certainly related to the oxidation of species containing Bi or/and $\mathrm{Cu}$ atoms, according to eqn (1) and $(2) .^{32}$

$$
\mathrm{Cu}+2 \mathrm{OH}^{-} \rightleftharpoons \mathrm{Cu}_{2} \mathrm{O}+\mathrm{H}_{2} \mathrm{O}+2 \mathrm{e}^{-}
$$

The existence of a unique redox feature in the low potential region (oxidation peak at $c a .+0.600 \mathrm{~V} v s$. RHE and reduction peak at $c a .+0.400 \mathrm{~V} v s$. RHE) for the $\mathrm{PtCuBi} / \mathrm{C}$ catalyst could be translated to a weaker interaction between the Pt and the oxide species from $\mathrm{Cu}$ and $\mathrm{Bi}$ that could be present at the surface ${ }^{47}$ compared to that observed in the higher potential range (oxidation peak at $c a .+0.900 \mathrm{~V} v s$. RHE and reduction peak at $c a$. $+0.700 \mathrm{~V} v s$. RHE).

The GIXRD and electrochemical results confirm that in $\mathrm{PtCu}$ clusters, $\mathrm{Pt}$ and $\mathrm{Cu}$ form a uniform alloy with a strong interaction between $\mathrm{Pt}$ and $\mathrm{Cu}$ atoms at the surface. The electrochemical response of the PtBi catalyst is aligned with the assumption that Bi atoms are on the cluster surface as observed by STEM in Fig. 7 and decorate Pt clusters. In the case of the $\mathrm{PtCuBi} / \mathrm{C}$ catalyst, the results for both $\mathrm{PtCu} / \mathrm{C}$ and $\mathrm{PtBi} / \mathrm{C}$ could indicate the possible electrochemical response of an alloyed $\mathrm{PtCu}$ cluster decorated with Bi species. However, the CVs show that a portion of the $\mathrm{Cu}$ atoms is on the cluster surface, and the unique oxidation peak at $0.580 \mathrm{~V}$ vs. RHE represents the formation of a structure where $\mathrm{Bi}$ and $\mathrm{Cu}$ surface atoms are also in strong interaction. As mentioned before, the presence of a $\mathrm{Cu}-\mathrm{Bi}$ metastable phase cannot be discarded and a structure consisting in a $\mathrm{PtCu}$ core decorated with amorphous $\mathrm{Cu}-\mathrm{Bi}$ could also be proposed.

The activity of the Pt-based catalysts towards the electrooxidation of $0.10 \mathrm{~mol} \mathrm{~L}^{-1}$ glycerol in a $\mathrm{N}_{2}$-purged $0.10 \mathrm{~mol} \mathrm{~L}^{-1}$ $\mathrm{NaOH}$ electrolyte is compared in Fig. 9. The metal loadings on electrodes are in a very narrow range from $0.08 \pm 0.01 \mathrm{mg}_{\text {metal }}$ $\mathrm{cm}^{-2}$ to $0.10 \mathrm{mg}_{\text {metal }} \mathrm{cm}^{-2}$, increasing with addition of $\mathrm{Cu}, \mathrm{Bi}$ and $\mathrm{CuBi}$ to Pt; therefore, the influence of the metal loading on the electrode will have a negligible effect compared with that of the cluster composition. The $\mathrm{Pt} / \mathrm{C}$ catalyst (black curve) leads to an oxidation onset potential of $c a .+0.400 \mathrm{~V} v s$. RHE, which is consistent with other previous studies realized on $\mathrm{Pt} / \mathrm{C}$ and $\mathrm{Pt}_{x} \mathrm{Bi}_{1-x}$ materials prepared by wet chemistry. ${ }^{3,9,47}$ The addition of Bi to Pt leads to a slight shift of the onset potential towards a lower value and slightly higher activity between $c a .+0.380 \mathrm{~V} v s$. 


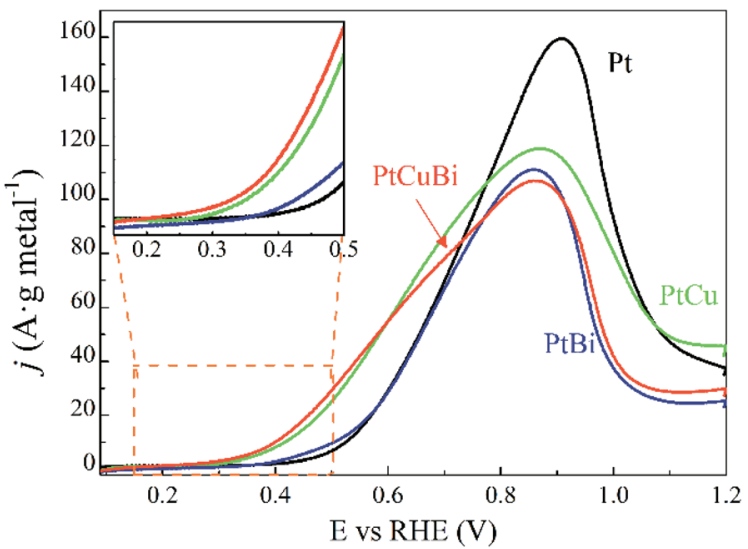

Fig. 9 Polarization curves for the oxidation of $0.10 \mathrm{~mol} \mathrm{~L}^{-1}$ glycerol recorded for $\mathrm{Pt} / \mathrm{C}$ (black line), $\mathrm{PtBi} / \mathrm{C}$ (blue line), $\mathrm{PtCu} / \mathrm{C}$ (green line) and $\mathrm{PtCuBi} / \mathrm{C}$ (red line) materials $\left(v=0.005 \mathrm{~V} \mathrm{~s}^{-1}, \mathrm{~N}_{2}\right.$-saturated $0.10 \mathrm{M}$ $\mathrm{NaOH}$ electrolyte, $T=20^{\circ} \mathrm{C}$ ). Inset: zoomed-in image of the oxidation potential onset region.

RHE and $c a .+0.600 \mathrm{~V} v s$. RHE, as higher currents (mass activities) are recorded over this potential range. For potentials higher than $0.700 \mathrm{~V} v s$. RHE, Pt/C displays higher activity than $\mathrm{PtBi} / \mathrm{C}$. The low increase of mass activity at low potentials and the lower mass activity achieved at higher potentials demonstrate that the $\mathrm{Bi}$ atomic ratio is relatively high, higher than 10 at $\%,{ }^{8}$ in agreement with cyclic voltammetry measurements, hindering the active platinum surface. This definitively confirms that the estimation of the Bi atomic ratio in the clusters is underestimated by EDX. In contrast, the addition of $\mathrm{Cu}$ to Pt leads to a significant shift of the onset potential towards a lower value and to a huge increase of the mass activities in the potential range from $+0.280 \mathrm{~V}$ to $+0.800 \mathrm{~V}$ vs. RHE. PtCuBi/C leads to a lower oxidation onset potential of $c a .+0.250 \mathrm{~V} v s$. RHE and to slightly higher activity in the $+0.250 \mathrm{~V}$ to $+0.600 \mathrm{~V} v s$. RHE potential range. Between +0.600 and $+0.800 \mathrm{~V} v s$. RHE, $\mathrm{PtCu}$ becomes the best catalyst. For example, the mass activity achieved at $+0.600 \mathrm{~V} v s$. RHE on the $\mathrm{PtCu}$ and $\mathrm{PtCuBi} / \mathrm{C}$ catalysts (ca. $55 \mathrm{~A} \mathrm{~g}_{\text {metal }}{ }^{-1}$ ) is twice higher than that recorded on the $\mathrm{Pt} / \mathrm{C}$ catalyst ( $c a .30 \mathrm{~A} \mathrm{~g}_{\text {metal }}{ }^{-1}$ ). These activity values are very close to those reported under the same experimental conditions (0.10 mol L ${ }^{-1}$ glycerol, $\mathrm{N}_{2}$-saturated $0.10 \mathrm{~mol} \mathrm{~L}^{-1} \mathrm{NaOH}$ electrolyte, scan rate of $0.005 \mathrm{~V} \mathrm{~s}^{-1}$ and $20^{\circ} \mathrm{C}$ ) by Kouamé et al. ${ }^{8}$ on $\mathrm{Pt} / \mathrm{C}$ and $\mathrm{PtBi} / \mathrm{C}$ catalysts prepared by wet chemistry ("water in oil" microemulsion), i.e. between 40 and $70 \mathrm{~A} \mathrm{~g}_{\text {metal }}{ }^{-1}$. At $0.800 \mathrm{~V} v s$. RHE, the Pt/C catalyst prepared using the GAS leads to higher activity (mass activity of $120 \mathrm{~A} \mathrm{~g}_{\text {metal }}{ }^{-1}$ ) than that prepared by wet chemistry (mass activity of $100 \mathrm{~A} \mathrm{~g}_{\text {metal }}{ }^{-1}$ ). ${ }^{8}$ These results seem to indicate that the $\mathrm{Pt} / \mathrm{C}$ catalyst prepared using the GAS is more prone to poisoning at potentials lower than $0.700 \mathrm{~V} v s$. RHE, but more active at potentials higher than $0.800 \mathrm{~V} v s$. RHE than the one prepared by wet chemistry. Both catalysts are composed of Pt NPs with a mean size of $c a .5 \mathrm{~nm}$ dispersed on the same carbon support (Vulcan XC 72), with the same metal weight loading (40 wt\%) and almost the same surface concentrations $\left(0.100 \mathrm{mg} \mathrm{cm}^{-2}\right.$ for the wet chemistry Pt/ C catalyst and 0.080 for the GAS Pt/C catalyst). Therefore, the difference in activity is not due to the size effect or agglomeration effect but rather seems to be due to the Pt surface structure effect. Indeed, the TEM image in Fig. 5a displays faceted Pt NPs, whereas Pt nanoparticles obtained by wet chemistry were round-shaped, ${ }^{8}$ and it is well known that the surface structure of Pt NPs has a huge effect on poisoning and electro-activity. ${ }^{48-50}$

Moreover, the potential range over which the $\mathrm{PtCu} / \mathrm{C}$ and $\mathrm{PtCuBi} / \mathrm{C}$ catalysts are active is wider than that for $\mathrm{Pt} / \mathrm{C}$, which can have an impact on the selectivity of the reaction with respect to the electrode potential. Indeed, at least two oxidation processes occur on $\mathrm{PtCu} / \mathrm{C}$ and $\mathrm{PtCuBi} / \mathrm{C}$ leading to the main peak with a shoulder at lower potentials, whereas Pt/C leads only to one oxidation peak. However, it was previously shown ${ }^{8,51}$ that the species formed during the glycerol electrooxidation on Pt-based catalysts also depend on the electrode potential. In alkaline media, the formations of products such as glyceraldehyde and dihydroxyacetone in a lower proportion are promoted below $+0.600 \mathrm{~V}$ vs. RHE. Above $+0.700 \mathrm{~V}$ vs. RHE, mostly carboxylate species such as glycerate or tartronate are

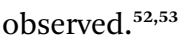

The role of bismuth in the activity enhancement at low potentials was proposed to come from the promotion of both a geometric effect (dilution of adjacent Pt atoms) that favors a particular adsorption mode of glycerol on Pt sites avoiding multi-bonding and/or dissociative adsorption leading to adsorbed CO poisoning the catalyst surface and from a strong electronic effect between Pt and Bi that favors the desorption of less oxidized species like glyceraldehyde and dihydroxyacetone (DHA). But for a Bi ratio higher than 10 at $\%$, the activity was not significantly improved, likely due to too high Pt surface coverage. $^{8}$

The presence of $\mathrm{Cu}$ in the catalyst can also modify the oxidation mechanism at low potentials. ${ }^{54}$ It has been shown that alloying $\mathrm{Cu}$ with $\mathrm{Pt}$ led to a downshift of the d-band

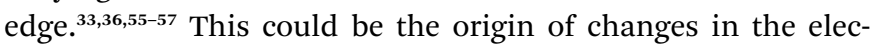
trochemical reactivity by favoring, at low electrode potentials, the adsorption of hydroxyl groups on copper atoms that can be used as extra-oxygen atoms to complete the electro-oxidation reaction towards carboxylate (bifunctional mechanism) according to eqn (3) (considering the only formation of glycerate):

$$
\begin{aligned}
& \mathrm{CH}_{2} \mathrm{OH}-\mathrm{CHOH}-\mathrm{CH}_{2} \mathrm{OH}+5 \mathrm{OH}^{-} \rightarrow \\
& \mathrm{CH}_{2} \mathrm{OH}-\mathrm{CHOH}-\mathrm{COO}^{-}+4 \mathrm{H}_{2} \mathrm{O}+4 \mathrm{e}^{-}
\end{aligned}
$$

This mechanism will increase the desorption rate, liberating free Pt sites for further glycerol adsorption and increasing the overall reaction rate..$^{52,53,58}$ But in this case, the selectivity will be towards carboxylate species even in the low potential region. Therefore, the use of Bi as well as of $\mathrm{Cu}$ can improve the activity and alter the selectivity and the oxidation rate that lead to molecules with high added-value. ${ }^{52,59,60}$

\section{Conclusions}

Modification of the sputtering power applied to the three metallic targets $(\mathrm{Pt}, \mathrm{Bi}$, and $\mathrm{Cu})$ located in a gas aggregation 
source allows production of mono, bi and trimetallic clusters with average sizes below $6 \mathrm{~nm}$. In situ (quadrupole mass spectrometry) and ex situ (EDX-STEM mapping and Grazing Incidence X-ray diffraction) techniques show the effect of the cosputtering of $\mathrm{Pt}$ and $\mathrm{Cu}$ or $\mathrm{Bi}$ on the growth and on the characteristics of the resulting clusters. Increasing the sputtering power enhances the total deposited mass and the number of $\mathrm{Pt}$ and $\mathrm{PtCu}$ clusters. However, in the case of $\mathrm{Pt}$ and $\mathrm{Bi}$ cosputtering, the total mass deposited and the number of produced clusters decrease for a Bi sputtering power exceeding the limit value of $8 \mathrm{~W}$. Addition of $\mathrm{Cu}$ leads to the formation of a homogeneous PtCu alloy (as confirmed by GIXRD and EDXSTEM mapping images) that decreases the Pt lattice parameter as a function of the sputtering power. For ternary clusters, detailed information on the nanostructure obtained from EDXSTEM mapping images indicated the formation of a $\mathrm{PtCu}$ alloyed core surrounded by Bi atoms. However, electrochemical characterization of the $\mathrm{PtCuBi} / \mathrm{C}$ catalysts could also indicate an additional structure such as an alloyed $\mathrm{PtCu}$ core decorated with amorphous $\mathrm{Cu}-\mathrm{Bi}$ species.

This structure has a deep impact on the electrochemical response of the Pt-based clusters during the electrooxidation of glycerol. Addition of $\mathrm{Cu}$ and $\mathrm{Bi}$ leads to a decrease of the oxidation onset potential. The presence of $\mathrm{Cu}$ increases the oxidation current in a broad range of potentials while the presence of Bi only increases the current in a narrower potential range. The $\mathrm{PtCuBi} / \mathrm{C}$ catalyst reveals both $\mathrm{Cu}$ and $\mathrm{Bi}$ features: higher oxidation currents and a larger oxidation potential range that lead to the lowest onset potential in our series of Pt-based catalysts and to the higher activity below $+0.600 \mathrm{~V} v s$. RHE, with $\mathrm{PtCu}$ remaining the most active between $+0.600 \mathrm{~V}$ and $+0.800 \mathrm{~V}$ $v s$. RHE. Therefore, a plasma magnetron-based gas aggregation source can be used for tailoring Pt-based multimetallic clusters for applications in electrocatalysis.

\section{Conflicts of interest}

The authors declare no competing financial or commercial interest.

\section{Acknowledgements}

This work was funded by the French "Agence Nationale de la Recherche" under grant ANR-16-CE29-0007 (ECO-PLAN project) and by the CNRS PEPS project Dust4Pem. All the authors acknowledge Olivier Weldling and Thierry Sauvage from CEMHTI laboratory (Orléans) for the RBS analysis. The authors thank Audrey Sauldubois (CME, Orléans) and Jaafar Ghanbaja (IJL, Nancy) for the HRTEM measurements and Thomas Lecas and Nicolas Dumuis for technical support on the gas aggregation source.

\section{References}

1 S. K. Duran, Mater. Today: Proc., 2020, 26, 261-265.

2 K. Hanaki and J. Portugal-Pereira, in Biofuels and Sustainability: Holistic Perspectives for Policy-making, ed. K.
Takeuchi, H. Shiroyama, O. Saito and M. Matsuura, Springer Japan, Tokyo, 2018, pp. 53-71.

3 M. Simões, S. Baranton and C. Coutanceau, ChemSusChem, 2012, 5, 2106-2124.

4 H. W. Tan, A. R. Abdul Aziz and M. K. Aroua, Renewable Sustainable Energy Rev., 2013, 27, 118-127.

5 M. Pagliaro, R. Ciriminna, H. Kimura, M. Rossi and C. Della Pina, Angew. Chem., Int. Ed., 2007, 46, 4434-4440.

6 J. C. Beltrán-Prieto, K. Kolomazník and J. Pecha, Aust. J. Chem., 2013, 66, 511-521.

7 G. Dodekatos, S. Schünemann and H. Tüysüz, ACS Catal., 2018, 8, 6301-6333.

8 B. S. R. Kouamé, S. Baranton, P. Brault, C. Canaff, W. Chamorro-Coral, A. Caillard, K. De Oliveira Vigier and C. Coutanceau, Electrochim. Acta, 2020, 329, 135161.

9 M. Simões, S. Baranton and C. Coutanceau, Electrochim. Acta, 2010, 56, 580-591.

10 A. A. Alekseenko, S. V. Belenov, V. S. Menshikov and V. E. Guterman, Russ. J. Electrochem., 2018, 54, 415-425.

11 H. Yang, L. Dai, D. Xu, J. Fang and S. Zou, Electrochim. Acta, 2010, 55, 8000-8004.

12 J. Maya-Cornejo, R. Carrera-Cerritos, D. Sebastián, J. Ledesma-García, L. G. Arriaga, A. S. Aricò and V. Baglio, Int. J. Hydrogen Energy, 2017, 42, 27919-27928.

13 O. Kylián, V. Valě̌, O. Polonskyi, J. Pešička, J. Čechvala, P. Solař, A. Choukourov, D. Slavínská and H. Biederman, Mater. Lett., 2012, 79, 229-231.

14 O. Kylián, J. Prokeš, O. Polonskyi, J. Čechvala, J. Kousal, J. Pešička, J. Hanuš and H. Biederman, Thin Solid Films, 2014, 571, 13-17.

15 M. Vaidulych, J. Hanuš, J. Kousal, S. Kadlec, A. Marek, I. Khalakhan, A. Shelemin, P. Solař, A. Choukourov, O. Kylián and H. Biederman, Plasma Processes Polym., 2019, 16, 1900133.

16 O. Kylián, J. Kratochvíl, J. Hanuš, O. Polonskyi, P. Solař and

H. Biederman, Thin Solid Films, 2014, 550, 46-52.

17 D. Nelli, A. Krishnadas, R. Ferrando and C. Minnai, J. Phys. Chem. C, 2020, 124, 14338-14349.

18 A. Wurl, M. Hyslop, S. A. Brown, B. D. Hall and R. Monot, Eur. Phys. J. D, 2001, 16, 205-208.

19 M. Broyer, B. Cabaud, A. Hoareau, P. Melinon, D. Rayane and B. Tribollet, in Physics and Chemistry of Small Clusters, ed. P. Jena, B. K. Rao and S. N. Khanna, Springer US, Boston, MA, 1987, pp. 277-281.

20 L. Martínez, M. Díaz, E. Román, M. Ruano, D. Llamosa and P. Y. Huttel, Langmuir, 2012, 28, 11241-11249.

21 G. E. Johnson, R. Colby, M. Engelhard, D. Moon and J. Laskin, Nanoscale, 2015, 7, 12379-12391.

22 V. Singh, C. Cassidy, P. Grammatikopoulos, F. Djurabekova, K. Nordlund and M. Sowwan, J. Phys. Chem. C, 2014, 118, 13869-13875.

23 G. E. Johnson, R. Colby and J. Laskin, Nanoscale, 2015, 7, 3491-3503.

24 D. Llamosa, M. Ruano, L. Martínez, A. Mayoral, E. Roman, M. García-Hernández and Y. Huttel, Nanoscale, 2014, 6, 13483-13486. 
25 A. Caillard, S. Cuynet, T. Lecas, P. Andreazza, M. Mikikian, A.-L. Thomann and P. Brault, J. Phys. D: Appl. Phys., 2015, 48, 475302.

26 W. Chamorro-Coral, A. Caillard, P. Brault, P. Andreazza, C. Coutanceau and S. Baranton, Plasma Processes Polym., 2019, 16, e1900006.

27 K. Momma and F. Izumi, J. Appl. Crystallogr., 2011, 44, 12721276.

28 Materials Project, https://materialsproject.org/, accessed 10 September 2019.

29 A. J. R. Botz, M. Nebel, R. A. Rincón, E. Ventosa and W. Schuhmann, Electrochim. Acta, 2015, 179, 38-44.

30 J. Gonzalez-Cobos, S. Baranton and C. Coutanceau, ChemElectroChem, 2016, 3, 1694-1704.

31 D. E. Newbury and N. W. E. Ritchie, Scanning, 2013, 35, 141168.

32 W. M. Haynes, CRC handbook of chemistry and physics, CRC Press, 97th edn, 2016.

33 X. Peng, Y. Zhao, D. Chen, Y. Fan, X. Wang, W. Wang and J. Tian, Electrochim. Acta, 2014, 136, 292-300.

34 M. Gao, W. Yang and Y. Yu, Int. J. Hydrogen Energy, 2018, 43, 14293-14300.

35 L. Leppert, R. Q. Albuquerque and S. Kümmel, Phys. Rev. B: Condens. Matter Mater. Phys., 2012, 86, 241403.

36 V. Petkov, Y. Maswadeh, J. A. Vargas, S. Shan, H. Kareem, Z.-P. Wu, J. Luo, C.-J. Zhong, S. Shastri and P. Kenesei, Nanoscale, 2019, 11, 5512-5525.

37 K. T. Jacob, S. Raj and L. Rannesh, Int. J. Mater. Res., 2007, 98, 776-779.

38 R. Tran, Z. Xu, B. Radhakrishnan, D. Winston, W. Sun, K. A. Persson and S. P. Ong, Sci. Data, 2016, 3, 160080.

39 D. Nafday, S. Sarkar, P. Ayyub and T. Saha-Dasgupta, ACS Nano, 2018, 12, 7246-7252.

40 H. J. Wasserman and J. S. Vermaak, Surf. Sci., 1972, 32, 168174.

41 J. Solla-Gullón, P. Rodríguez, E. Herrero, A. Aldaz and J. M. Feliu, Phys. Chem. Chem. Phys., 2008, 10, 1359-1373.

42 P. Rodríguez, J. Solla-Gullón, F. J. Vidal-Iglesias, E. Herrero, A. Aldaz and J. M. Feliu, Anal. Chem., 2005, 77, 5317-5323.
43 J. Z. Chen, Z. Wu, X. Zhang, S. Choi, Y. Xiao, A. Varma, W. Liu, G. Zhang and J. T. Miller, Catal. Sci. Technol., 2019, 9, 1349-1356.

44 O. Teppo, J. Niemelä and P. Taskinen, Thermochim. Acta, 1990, 173, 137-150.

45 D. J. Chakrabarti and D. E. Laughlin, Bull. Alloy Phase Diagrams, 1984, 5, 148-155.

46 R. M. Castagna, J. M. Sieben, A. E. Alvarez and M. M. E. Duarte, Int. J. Hydrogen Energy, 2019, 44, 5970-5982. 47 C. Coutanceau, A. Zalineeva, S. Baranton and M. Simoes, Int. J. Hydrogen Energy, 2014, 39, 15877-15886.

48 J. F. Gomes, F. B. C. de Paula, L. H. S. Gasparotto and G. Tremiliosi-Filho, Electrochim. Acta, 2012, 76, 88-93.

49 A. Zalineeva, S. Baranton and C. Coutanceau, Electrochim. Acta, 2015, 176, 705-717.

50 R. M. L. M. Sandrini, J. R. Sempionatto, G. Tremiliosi-Filho, E. Herrero, J. M. Feliu, J. Souza-Garcia and C. A. Angelucci, ChemElectroChem, 2019, 6, 4238-4245.

51 C. Coutanceau, S. Baranton and R. S. B. Kouamé, Front. Chem., 2019, 7, 100.

52 Y. Kwon, Y. Birdja, I. Spanos, P. Rodriguez and M. T. M. Koper, ACS Catal., 2012, 2, 759-764.

53 N. Worz, A. Brandner and P. Claus, J. Phys. Chem. C, 2010, 114, 1164-1172.

54 P. N. Amaniampong, Q. T. Trinh, J. J. Varghese, R. Behling, S. Valange, S. H. Mushrif and F. Jérôme, Green Chem., 2018, 20, 2730-2741.

55 B. Chen, D. Cheng and J. Zhu, J. Power Sources, 2014, 267, 380-387.

56 Y. Kang, B. Jiang, Z. A. Alothman, A. Y. Badjah, M. Naushad, M. Habila, S. Wabaidur, J. Henzie, H. Li and Y. Yamauchi, Chem.-Eur. J., 2019, 25, 343-348.

57 O. B. Ayodele, R. Cai, J. Wang, Y. Ziouani, Z. Liang, M. C. Spadaro, K. Kovnir, J. Arbiol, J. Akola, R. E. Palmer and Y. V. Kolen'ko, ACS Catal., 2020, 10, 451-457.

58 A. C. Garcia, Y. Y. Birdja, G. Tremiliosi-Filho and M. T. M. Koper, J. Catal., 2017, 346, 117-124.

59 R. Ciriminna, A. Fidalgo, L. M. Ilharco and M. Pagliaro, ChemistryOpen, 2018, 7, 233-236.

60 D. Liu, J.-C. Liu, W. Cai, J. Ma, H. B. Yang, H. Xiao, J. Li, Y. Xiong, Y. Huang and B. Liu, Nat. Commun., 2019, 10, 1779. 